\title{
ARGUS blinked
}

You're being watched.

\section{Paul Di Filippo}

My cat was watching me at my workstation. And so was everyone else in the world. Nowadays we all live in a real-time Panopticon. Thanks to ARGUS.

ARGUS is the ARchive of Globally Uploaded Sensoria, and it contains every second of what every person on Earth sees or hears, even while they're asleep. An array of deer-tick-sized cameras and mics, powered by ambient-energy harvesting and embedded just under an individual's skin, takes care of the continuous volitionless recording.

The cameras and mics resemble a small facial tattoo, generally one on each cheek for stereo processing. The default manufacturer's design is an iconographic Eye of Horus, but hardly anyone out of eight billion citizens sticks with the default.

Growing up with ARGUS, I never had any real complaints, especially as it made my current job possible.

But then came that one disturbing day.

My name is Ross Strucker, and I'm an auteur. I turn the lives of ordinary people into art. Or I did, until I put down my digital toolkit forever.

The day ARGUS blinked, I was composing a romantic thriller. I was trying fruitlessly to find a shot in the ARGUS archives that included my two main players from a third perspective. That's often hard to do when only the two people in question are present together, regarding each other. Lots of times I can find surveillance-cam footage that does the trick. But not this time.

So, reluctantly, I turned to pet-cam footage. I generally dislike using footage from the Eyes of Horus installed in dogs, cats, pigeons and other animals, as it frequently represents weird camera angles and abrupt shifts in focus. But this time I found something suitable.

Satisfied yet tired, I took a break, and considered my palette of subsequent narrative choices. ARGUS offers so much to select from, after all.

The whole world in a gem. The many, many petabytes that make up ARGUS are mirrored across redundant sites, each store comprising 60 kilograms of artificial memory diamond, whose carbon-12/ carbon-13 lattice is only half full after 50 years of global input.
The instant-by-instant wireless feed from an individual's Eyes of Horus, tagged with a unique civic identifier, flows steadily into ARGUS itself, becoming merged with the citizen's lifestream to date.

The overwhelming majority of ARGUS data are open-source: privacy and secrecy died as soon as ARGUS came online. Anything that one person knows or experiences can be known and used by anybody else.

My cat jumped into my lap, seeking

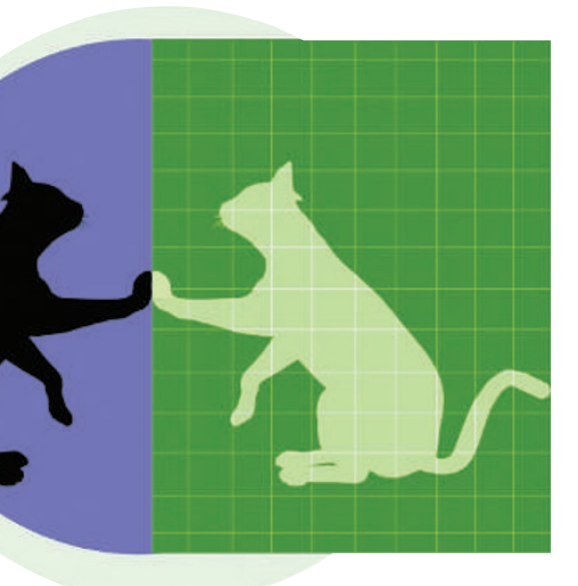

attention I couldn't really spare. I was too busy pondering the fates of my characters, wondering how I could improve on the vast tapestry of raw realism contained in ARGUS.

The footage (we auteurs prefer the oldfashioned term) that every citizen provides is automatically tagged with a plethora of descriptive labels for every second, identifying its content a thousand different ways. Semantics-savvy retrieval engines can bring up selections effortlessly according to their commonplace content.

Show me what I had for dinner a year ago today.

What my ex-wife is doing right now.

Who met with the Emir of Paris at ten this morning.

When my son last took a bath. What outfit Steffi Chubb is planning to wear to the Vatican Awards in Lagos tonight.

But my special auteurs' toolkit of semiintelligent aesthetic agents allows me to select footage on a more arcane basis.

Show me a set of ironic responses to failed plans.

A set of nostalgic daydreamers in bucolic settings.
A set of locales that convey desuetude mixed with menace.

A set of stifled orgasms.

Out of the raw material trawled up from the depths of ARGUS and displayed on my wall-sized Coldfire monitor, I assemble narratives and stories. My work falls midway between the oneiric, surreal montages of such auteurs as The Culling House Collective, Armand Akimbo and the Voest Twins, and documentarians like Nilda Osborne, Focal Length Unlimited and the Informavore.

Just then, my cat decided it would get no affection from me, and chose instead to regard the ARGUS monitor with feline curiosity, looking at the screen as if it truly comprehended the cycling images from its animal compatriots on display there.

On a juvenile whim, I decided to create an endless-hall effect, the simple result of any camera trained on a live monitor accepting that camera's feed.

I was already in the pet-cam area of ARGUS, so it was simple to open a window onto my cat's lifestream.

But instead of the endless hall, I saw something impossible. On my screen appeared an image of my cat looking out of my monitor, as if my cat's onboard Eyes had been transmitting an image from a mirror.

What was ARGUS doing? What unknown glitch could possibly account for this?

And then it struck me: ARGUS was looking back at us. The digitized lifestreams inside the titanic archive had bootstrapped themselves into awareness. The simulacrum of the world had passed a tipping point of information density.

I grew dizzy, faint. I closed my eyes. When I opened them, the impossible cat looking intelligently out had been replaced by the endless hall I had expected.

Bored, my cat leaped down and the moving point-of-view on the monitor shifted accordingly.

I hurriedly shut off my system.

And I still haven't turned it back on.

With thanks to Charles Stross and Rudy Rucker for their seminal insights into lifelogs and lifeboxes.

Paul Di Filippo, a Rhode Island native, has lived in the lovecraftian stomping grounds of Providence for the past 31 years. He sold his first story in 1977, and well over 100 since. His new novel, Cosmocopia, will appear in January 2008. 